\title{
Table of content
}

Plenary talks

\section{Talks}

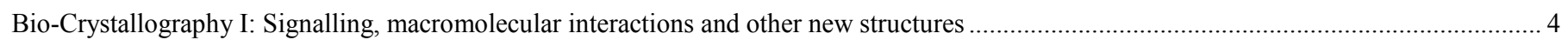

Inorganic crystal structures I ......

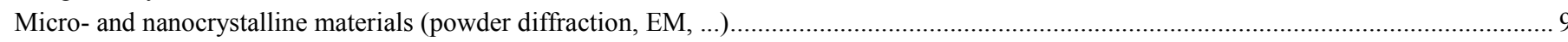

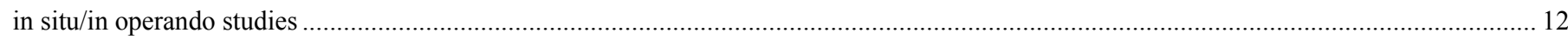

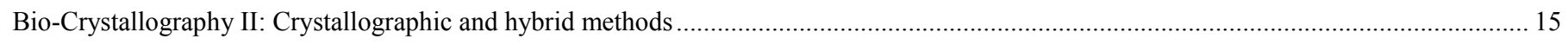

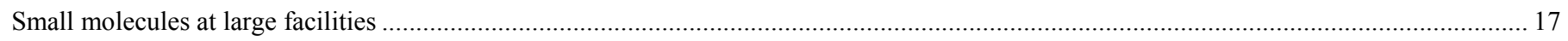

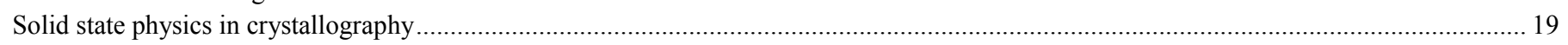

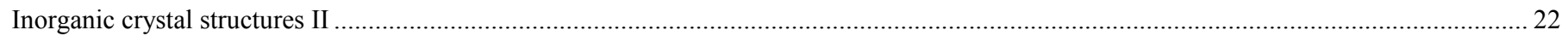

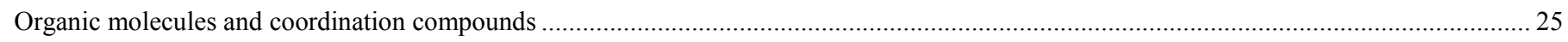

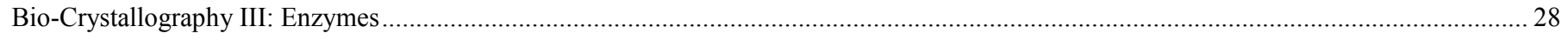

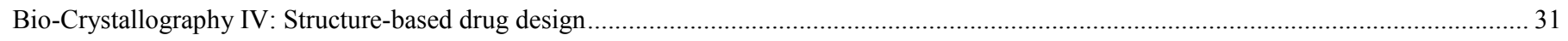

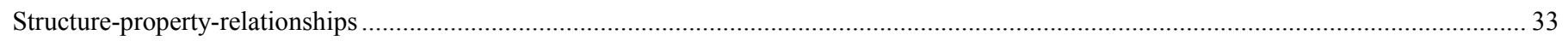

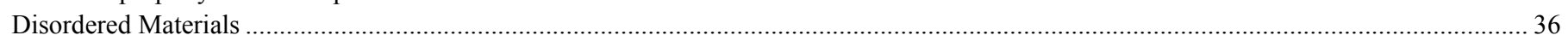

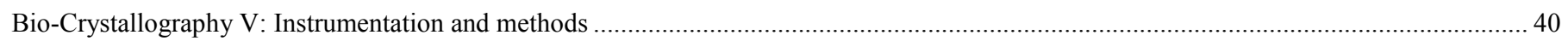

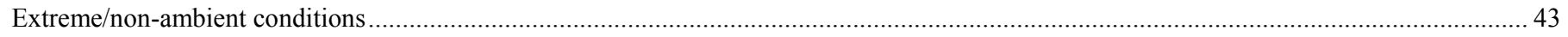

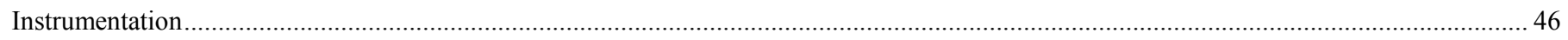

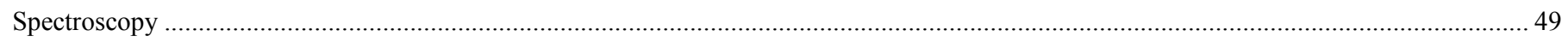

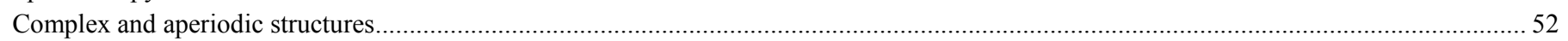

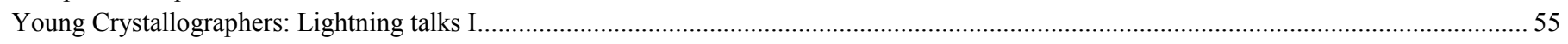

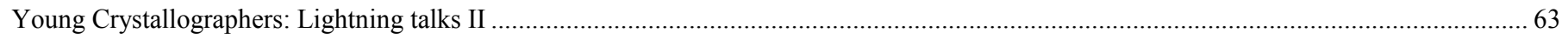

\section{Poster}

Bio-Crystallography I: Signalling, macromolecular interactions and other new structures .................................................................... 70

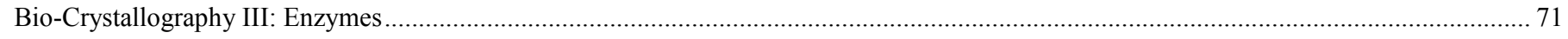

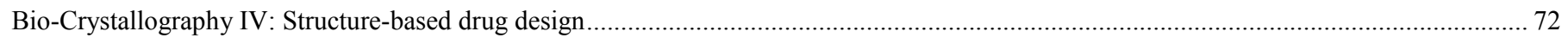

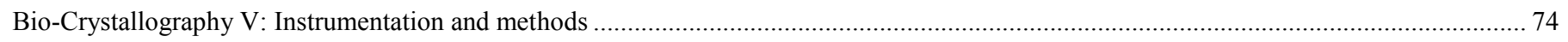

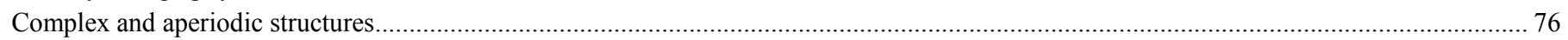

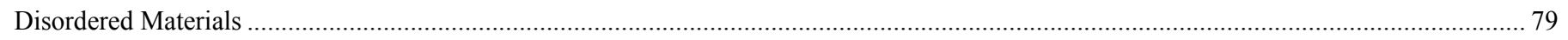

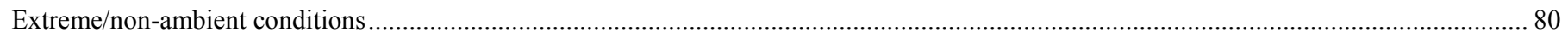

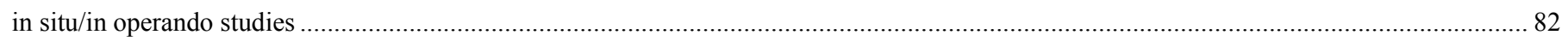

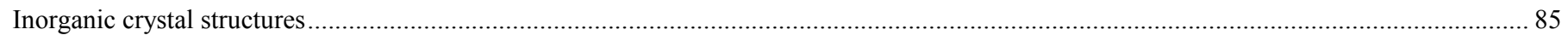

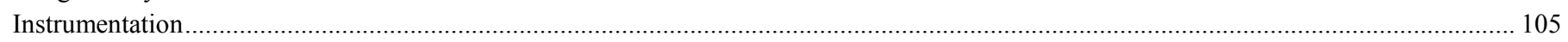

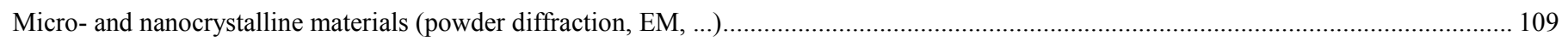

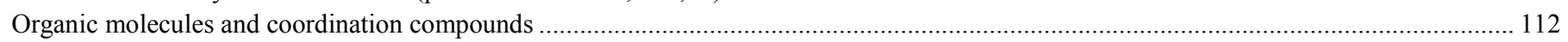

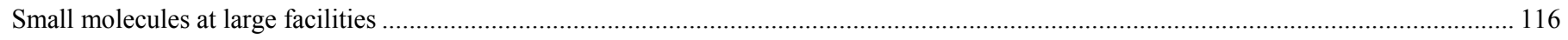

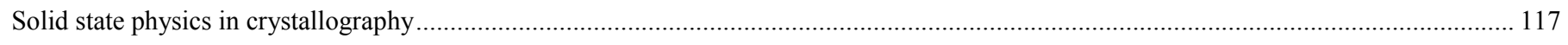

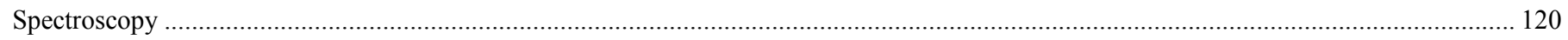

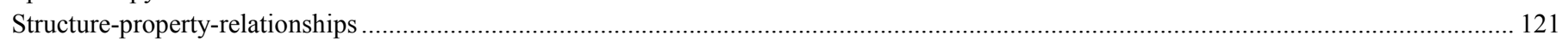

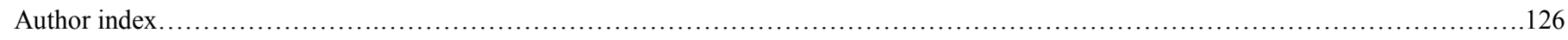

